\begin{tabular}{l}
\hline OPEN OA ACCESS Freely available online \\
http://www.banglajol.info/index.php/BJID/index \\
Original Article \\
Bangladesh Journal of Infectious Diseases \\
October 2020, Volume 7, Number Suppl_2, Page S27-S33 \\
ISSN (Online) 2411-670X \\
ISSN (Print) 2411-4820 DOI: https://doi.org/10.3329/bjid.v7i00.50159
\end{tabular}

\title{
Nurses' Knowledge and Practices Regarding Prevention and Control of COVID-19 Infection in a Tertiary Level Hospital
}

\author{
Ashees Kumar Saha ${ }^{1}$, China Rani Mittra ${ }^{2}$, Ronju Ara Khatun ${ }^{3}$, Hasan Mahfuz Reza ${ }^{4}$
}

${ }^{1}$ Senior Staff Nurse,Upazilla Health Complex, Bagha, Rajshahi, Bangladesh; ${ }^{2}$ Senior Staff Nurse, Upazilla Health Complex, Abhaynagar, Jashore, Bangladesh; ${ }^{3}$ Senior Staff Nurse, Rajshahi Medical College Hospital, Rajshahi, Bangladesh; ${ }^{4}$ Medical Officer, Urban Primary Health Care Services Delivery Project-II, Kushtia Municipality, Kushtia, Bangladesh

[Received: 17 August 2020; Accepted: 28 September 2020]

\begin{tabular}{|c|}
\hline \\
\hline $\begin{array}{l}\text { Background: Bangladesh is a highly populated country for that reasonCOVID-19 is highly transmittable } \\
\text { infection in Bangladesh. Objective: The aim of this study was to identify the nurses' knowledge and } \\
\text { practices regarding prevention and control of COVID-19 infection. Methodology: This cross-sectional } \\
\text { study was conducted in Rajshahi Medical College Hospital, Rajshahi, Bangladesh from April to July } 2020 \text {. } \\
\text { The questionnaires were completed and returned by the nurses. Collected data were checked, coded and } \\
\text { transferred in to SPSS version } 25 \text { for analysis. Frequency, percentage, mean, SD, chi-squire and other } \\
\text { statistics were calculated. Result: The knowledge and practices scores were categorized into good ( } \geq 80 \%) \text {, } \\
\text { fair (59-79\%), and poor. The result shows that majority of the respondents } 83.4 \% \text { were female and } 16.6 \% \\
\text { were male. Only } 8.68 \% \text { took training on COVID-19. More than half of the respondents }(52.11 \%) \text { took } \\
\text { information from social media and } 7.89 \% \text { from seminars and workshops. Nearly two third percent nurse's } \\
\text { possessed (73.42\%) good knowledge about COVID-19and } 17.63 \% \text { had fair knowledge.73.42\% nurses had } \\
\text { good practices, } 21.84 \% \text { fair practices and8.68\% poor practices. There is a significant relationship between } \\
\text { Nurses' knowledge and practices (p=0.01).Conclusion: In conclusion effective and appropriate health } \\
\text { education and training programs improve COVID-19 knowledge and maintenance of safe practices. Safe } \\
\text { practices lead to prevent spread of COVID-19 infection from patient to nurses and nurse to patient. } \\
\text { [Bangladesh Journal of Infectious Diseases, October } 2020 ; 7 \text { (suppl_2):S27-S33] }\end{array}$ \\
\hline $\begin{array}{l}\text { ywords: } \mathrm{Kn} \\
\text { pital }\end{array}$ \\
\hline $\begin{array}{l}\text { aff Nurse, Upazilla Health Complex, Bagha, Rajshahi, Bangladesh; Cell no.: } \\
\text { interest to declare. } \\
\text { d any funding from any person or any organization. } \\
\text { n protocol preparation, data collection and literature search up to manuscript } \\
\text { tun RA, Reza HM. Nurses' Knowledge and Practices Regarding Prevention and } \\
\text { Hospital. Bangladesh J Infect Dis 2020;7(suppl_2):S27-S33 } \\
\text { adesh Journal of Infectious Diseases. This article is published under the Creative } \\
\text { ommons.org/licenses/by-nc/4.0/). This license permits use, distribution and } \\
\text { work is properly cited, and is not used for commercial purposes. }\end{array}$ \\
\hline
\end{tabular}




\section{Introduction}

Since December 2019, the novel coronavirus disease (COVID-19) has spread from Wuhan city to other cities in China and around the world ${ }^{1}$. On March 11, 2020, the World Health Organization (WHO) declared the COVID-19 outbreak a pandemic. As of March 15, 2020, there had been 81,058 confirmed cases and 3204 deaths due to the virus in China.According to the WHO, the outbreak of coronavirus disease 2019 (COVID-19) has become a pandemic ${ }^{2}$.Amidst to current pandemic, WHO has issued several guidelines and also started online courses and training sessions to raise awareness and preparedness regarding prevention and control of COVID-19 among HCPs ${ }^{3}$. Knowledge and practice survey provides a suitable format to evaluate existing programs and to identify effective strategies for behaviour change in society ${ }^{4}$. Currently, there is scarce information regarding the awareness level of HCPs in Pakistan, Therefore, the present study aimed to identify the current status of knowledge and practices regarding COVID-19 among healthcare professionals in Bangladesh. Study will highlight the information sources utilized and training in infection control perceived by Nurses.

In December 2019, a rapidly infectious disease emerged in Wuhan city in China. The disease was caused by a member of the family of coronaviruses, finally named severe acute respiratory syndrome coronavirus 2 (SARS-CoV-2). The highly contagious virus, which caused the disease called coronavirus disease (COVID-19), spread outside China and has since become a global public health emergency ${ }^{5}$. In severe cases, the virus causes fatal pneumonia similar to that caused by severe acute respiratory syndrome coronavirus (SARS-CoV), and Middle East respiratory syndrome coronavirus (MERS-CoV), which have emerged in the past 20 years in sporadic countries all over the world ${ }^{6}$.

The clinical symptoms of COVID-19 include fever, which is the most common symptom, cough, fatigue, malaise, and shortness of breath. Global concerns about the virus have risen due to its high transmission capability, which may be coupled with morbidity and mortality ${ }^{7}$. The elderly and patients with comorbidities are more likely to be infected and are additionally more prone to serious complications, which may be associated with acute respiratory distress syndrome (ARDS) and cytokine storm $^{8}$.

COVID-19 transmits from person to person by droplets when an infected person sneezes and by direct contact and virus has an incubation period of 4-14 days ${ }^{9}$. Elderly and patients who suffered with chronic medical conditions like diabetes and cardiovascular diseases are more likely to get severe infection ${ }^{10}$.Till the moment, there is no proved treatment or vaccination against SARSCoV-2. Strong infection control measures are the primary intervention to minimize the spread of the virus in both health care settings and the community ${ }^{11}$. Vaccine development is estimated to require months, and thus management of the crisis depends primarily on people's adherence to the recommended measures taken. These measures are largely affected by knowledge, attitudes, and practices (KAP) of the public ${ }^{12}$.

In China, lessons learned from the SARS outbreak in 2003 suggest that knowledge and attitudes towards infectious diseases are associated with the level of panic emotion among the population, which can further complicate attempts to prevent the spread of the disease ${ }^{13}$.Behaviour's like underestimation, stigmatization, panic emotions, and false measures to avoid infection affect the battle against such an uncommon situation ${ }^{7}$.

In Bangladesh, the first case identified since 8 march. After one month the covid-19 patients gradually increasing daily average thousand. Bangladesh is a highly populated country here is chance for spread the infection rapidly. If the infection does not stop Bangladesh may disable to fight against covid-19. Nurses has an effective role to prevention and control the covid-19 infection. All nursing and midwifery staff are fundamental to informing the public and reassuring them about the COVID-19 outbreak ${ }^{14}$. The aim of this study was to identify the nurses' knowledge and practices regarding prevention and control of COVID-19 infection.

\section{Methodology}

This cross-sectional study was carried out for this investigation.The study was conducted in Rajshahi Medical College Hospital (RMCH), and it's a Governmental Tertiary Level Hospital.Total study period was 4 months from 1 April to 31 July 2020.Nurses of the Rajshahi Medical College Hospital (RMCH), was the study populations who give direct care to the patient.Purposive sampling technique was used. A survey instrument was designed based on extensive literature review and WHO infection prevention and control guidelines regarding COVID-19. After an initial draft of the questionnaire designed, it was validated in 2 steps. Firstly, the study instrument was sent to researchers 
and professionals from medical background to give their expert opinion with respect to its simplicity, relativity and importance. Secondly, a pilot study was conducted by selecting a small sample of Nurses $(n=40)$ who gave their opinions on making the questionnaire simpler and shorter. Amendments from the participants were considered and integrated into the questionnaire, while ensuring its consistency with the published literature. After a thorough discussion, questionnaire was finalized by the authors and subsequently distributed to the participants for their response. The data of the pilot study was not used for the final analysis. The questionnaire was consisted of questions assessing demographics, information source, knowledge and practices toward COVID-19. Demographic characteristics included were Age, Gender, Religion, Educational qualification Length of service, and one item regarding Training on COVID-19. Source of Information regarding COVID-19. It's included Social Media, Radio \& television, Seminars \& workshops, Posters \& Pamphlets, Newspapers \& Magazines, Seniors \& Other Colleagues and Online education. Knowledge section comprised of 10 items; regarding nature of disease (1-item), transmission (1-item), symptoms (1-item), Isolation(1-item), Vaccine(1-item), treatment(1-item), preventions (1-item)higher risk(2-items) and fatal (1-item). Seven questions were responded as one correct answer, one wrong answer and one don't know. Three questions were yes, No and don't know. The correct answer was marked as 1 while wrong answer and don't know was marked as 0 . Total score ranges from $0-10$ and it was then converted into percentage. A cut off level of $(\leq 50 \%)$ was set for poor knowledge (51$80 \%)$ fair knowledge and $(\geq 80 \%)$ for good knowledge ${ }^{15}$.Practice section included 19 items questions according to $\mathrm{WHO}$ infection prevention and control guidelines regarding COVID-19. Each item was responded as one correct answer, one wrong answer and one don't know. The correct answer was marked as 1 while wrong answer and don't know was marked as 0. Practice items total score ranged as $0-19$, and a score of and $(\geq 80 \%)$ demonstrated good practice, (59-79\%) demonstrated fair practices and a score of $(\leq 59 \%)$ indicates poor practice toward COVID-19 ${ }^{15}$. Written informed consent will be obtained from each respondent after explaining the purpose and procedure of the study with maintaining their full autonomy. Subjects' autonomy and confidentiality was strictly maintained. A permission letter taken from the director of Rajshahi Medical College Hospital. The researcher communicated with the Nursing Superintendent to select the eligible subjects to participate and informed the subjects about the objectives and the procedure of this study. Participation was voluntary and anonymity was guaranteed. Based on returning and completing the questionnaire by 384 nurses' considered as eligible subjects who signed written informed consent form and completed questionnaire in this study. Subjects could be withdrawn at any time without any reason. Manually and descriptive statistics calculated by using SPSS v.25.

\section{Results}

This descriptive cross-sectional study was carried out among 380 Nurses who were directly related to patient care working in Rajshahi Medical College Hospital, Rajshahi, Bangladesh.

Table 1: Demographic Characteristics of Respondents $(\mathbf{n}=\mathbf{3 8 0})$

\begin{tabular}{|l|c|c|}
\hline Attributes & Frequency & Percent \\
\hline Age (years) & 94 & 24.7 \\
\hline $25-35$ & 172 & 45.3 \\
\hline $36-45$ & 114 & 30 \\
\hline $46-55$ & 63 & 16.6 \\
\hline Gender & 317 & 83.4 \\
\hline Male & \multicolumn{2}{|l|}{} \\
\hline Female \\
\hline Religion & 16.57 \\
\hline Hindu & 76.57 \\
\hline Muslim & 291 & 1.57 \\
\hline Buddhist & 06 & 05 \\
\hline Christian & 19 & 56.3 \\
\hline Educational qualification \\
\hline Diploma in Nursing & 214 & 31.1 \\
\hline BSc in Nursing & 118 & 12.6 \\
\hline MSc in Nursing/ MPH & 48 & \\
\hline Length of service (years) \\
\hline 01 - 05 & 182 & 47.9 \\
\hline $06-10$ & 153 & 40.3 \\
\hline Above 10 & 11.8 \\
\hline Training on COVID-19 \\
\hline Yes & 33 & 8.68 \\
\hline No & 347 & 91.31 \\
\hline
\end{tabular}

From the respondents $24.7 \%$ were from $25-35$ years age group $45.3 \%$ from $36-45$ years age group and rest of them $30.0 \%$ from $46-55$ years. Majority of the respondents $83.4 \%$ were female and rest of them $16.6 \%$ were male. Among the respondents $76.57 \%$ were Muslim, $16.57 \%$ Hinduism, 05\% Christian and $1.57 \%$ Buddhist. Educational qualification of the respondents were $56.3 \%$ diploma in nursing $31.1 \mathrm{BSc}$ in nursing 
among them $12.6 \%$ had educational level up to MSc in Nursing/ MPH and almost half of the respondents $47.9 \%$ had length of service within 01 05 years, $40.3 \%$ had from $06-10$ years and rest of them 11.8 respondents had 10 years above. Training on COVID-19 0nly $8.68 \%$ took training (Table 1).

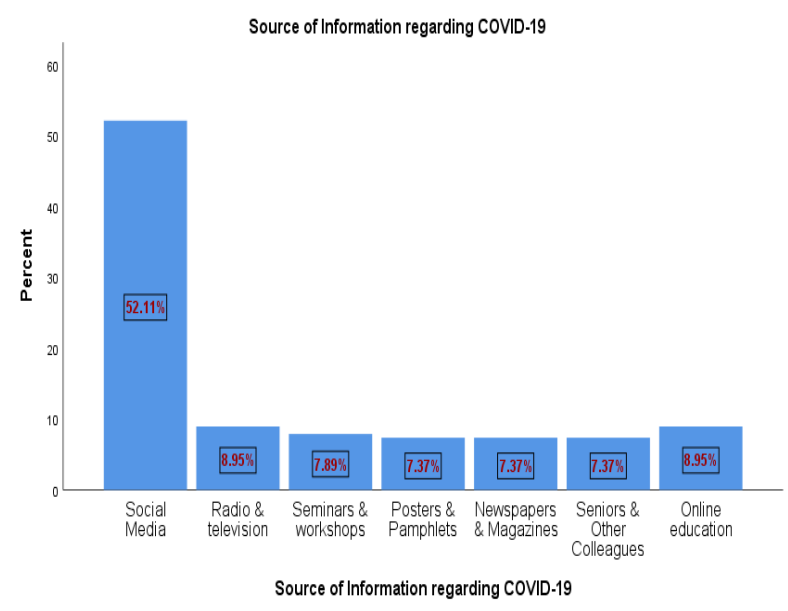

Figure I: Source of Information regarding COVID-19

Figure I shows above half of the respondents $52.11 \%$ took information from social media, $8.95 \%$ from radio \& television $7.89 \%$ from seminars \& workshops, posters $\&$ pamphlets, from newspapers $\&$ magazines and from seniors \& other colleagues $7.37 \%$ among them $8.95 \%$ from Online education

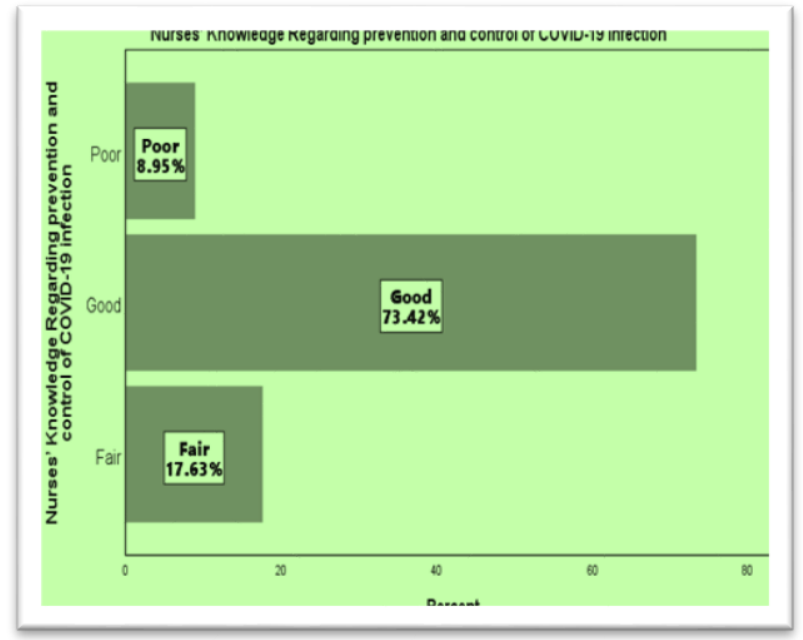

Figure II: Nurses' Knowledge Regarding prevention and control of COVID-19 infection $(n=380)$
Figure II shows the number and frequency of nurses who were in each category of knowledge level. It was found that $73.42 \%$ of Nurses possessed Good Knowledge $17.63 \%$ Nurses possessed Fair knowledge and rest of them $8.95 \%$ possessed Poor Knowledge regarding Prevention and Control of COVID-19 Infection.

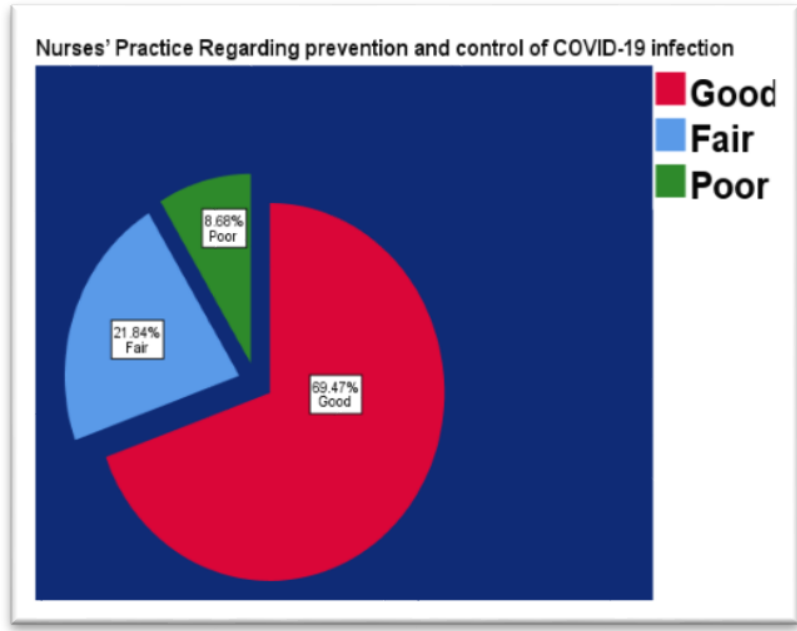

Figure III: Nurses' Practice Regarding prevention and control of COVID-19 infection $(\mathbf{n}=380)$

It was found that $8.68 \%$ nurses scored poor practices, nurses $21.84 \%$ scored fair practices and rest of them scored good practices (Figure III).

Table 2a: Frequency of Overall Knowledge and Practices Level of Nurse's according to Age, Gender, Education and Length of Services Regarding Prevention And Control of COVID19 Infection $(n=380)$

\begin{tabular}{|l|c|c|}
\hline Attributes & Frequency & Percent \\
\hline Age Group \\
\hline 25 to 35 Years & 94 & 24.7 \\
\hline 36 to 45 Years & 172 & 45.3 \\
\hline 46 to 55 Years & 114 & 30 \\
\hline Gender \\
\hline Male & 63 & 16.6 \\
\hline Female & 317 & 83.4 \\
\hline Educational Qualification \\
\hline Diploma in Nursing & 214 & 56.3 \\
\hline BSc in Nursing & 118 & 31.1 \\
\hline $\begin{array}{l}\text { MSc in Nursing/ } \\
\text { MPH }\end{array}$ & 48 & 12.6 \\
\hline Length of Services & 182 & 47.9 \\
\hline 1 to 5 Years & 40.3 \\
\hline 6 to 10 Years & 153 & 11.8 \\
\hline Above 10 Years & 45 & \\
\hline
\end{tabular}


Table 2b: Frequency of Overall Knowledge and Practices Level of Nurse's according to Age, Gender, Education and Length of Services Regarding Prevention And Control of COVID19 Infection $(n=380)$

\begin{tabular}{|l|c|c|}
\hline Attributes & $\begin{array}{c}\text { Knowledge } \\
\text { Level }\end{array}$ & $\begin{array}{c}\text { Practices } \\
\text { Level }\end{array}$ \\
\hline Age Group & Fair & Fair \\
\hline 25 to 35 Years & Good & Good \\
\hline 36 to 45 Years & Good & Good \\
\hline 46 to 55 Years & Good & Good \\
\hline Gender & Good & Fair \\
\hline Male & Good & Good \\
\hline Female & Poor \\
\hline Educational Qualification & Good \\
\hline Diploma in Nursing & Gair \\
\hline BSc in Nursing & Good \\
\hline $\begin{array}{l}\text { MSc in Nursing/ } \\
\text { MPH }\end{array}$ & \\
\hline Length of Services & Good & Good \\
\hline 1 to 5 Years & Good & Good \\
\hline 6 to 10 Years & Poor & Fair \\
\hline Above 10 Years
\end{tabular}

In this study 94 nurses were in the age group of 25 to 35 years and they scored fair knowledge and fair practice, 172 nurses' age in 36 to 45 years and they scored good knowledge and good practice and 114 nurses' age in 46 to 55 years and they scored good knowledge and good practice. Male were 63 cases and they scored good knowledge and good practices; however, female were 317 and they scored good knowledge and fair practices. Educational level of 214 nurses were diploma in nursing and they scored good knowledge and good practices, BSc in nursing was in 118 nurses and they fair knowledge and poor practices and MSc in nursing or MPH 48 nurses and they scored good knowledge and good practices. Length of services 1 to 5 years 182 nurses and they scored good knowledge and good practices, length of services 6 to 10 years 153 Nurses and they scored Good knowledge and Good practices and 45 Nurses above 10 years length of services and they scored poor knowledge and fair practices (Table $2 \mathrm{a} \& \mathrm{~b}$ ).

\section{Discussion}

COVID-19 infection now is a common problem all over the world. Therefore, up to date knowledge and nursing skills can play important roles inCOVID-19 infection control. Nurses should have the opportunity to practice infection control on a day-to-day basis as an integral part of patients' care. That is why the current study was carried out. In our study that was conducted at Rajshahi Medical College Hospital, revealed from the current study, nearly two thirds of the studied sample aged between 25 to 45 years old. This finding is in concordance with that of emphasizing the need to protect this group of workers in the prime of their life from hospital infections ${ }^{16-18}$.

Table 3: Pearson Product-Moment Correlation Coefficients between Nurses' Knowledge and Practice Regarding Prevention and Control of COVID-19 Infection $(n=380)$

\begin{tabular}{|l|c|c|}
\hline Pearson Correlation & 1 & $0.908^{* *}$ \\
\hline P value & & 0.000 \\
\hline $\mathrm{N}$ & 380 & 380 \\
\hline
\end{tabular}

Findings of current survey demonstrated that majority of Nurse's have good knowledge $(73.42 \%)$, and good practice $(69.47 \%)$ towards COVID-19. Of note that, $52.11 \%$ Nurse's utilized social media as a main source of information while only $7.89 \%$ seek information from seminars \& workshops. Findings are consistent with number of studies as Giao et $\mathrm{a}^{20}$ reported social media as a main source of information regarding COVID-19 used by $91.1 \%$ participant health care workers ${ }^{19}$. Similarly, a study conducted among 453 HCPs found that more than $61.0 \%$ respondents use social media to seek information regarding COVID-19.

This is important as in this global pandemic, there is also a pandemic of misinformation regarding COVID-19; a serious concern might lead to xenophobia in the world as already warned by scientists and WHO officials ${ }^{21}$. Also, there is plethora of malicious and unverified information waved on internet that spread quickly and could misguide the HCPs. So, situation demands that HCPs should carefully evaluate COVID-19 information sources and utilize authentic and valid content to seek information ${ }^{22}$.

Current findings of good knowledge among HCPs is in line with findings of Giao et $\mathrm{al}^{23}$ who reported that $88.4 \%$ participants have sufficient knowledge regarding COVID-19. Nemati et $\mathrm{al}^{24}$ also reported that $89.51 \%$ healthcare workers have claimed good knowledge while in another study conducted among nurses reported that $56.5 \%$ respondents have sufficient knowledge regarding transmission, symptoms and treatment of COVID-19. Present findings provide confidence in terms of healthcare professional's knowledge regarding COVID-19 symptoms, transmission and preventive measures. 
This is of more significance in current scenario when there is no vaccine and research is ongoing so Nurse's must aware of all the updates and take precautions in treating and preventing the infection.

Results revealed that majority of Nurse's have good practice in following precautionary measures. Highest good practice was observed in washing hands with soap which is similar to the findings of Khan et $\mathrm{al}^{25}$ and Nour et $\mathrm{al}^{26}$ who reported $95.4 \%$ and $85.7 \%$ HCPs used to wash their hands continuously.

Findings demonstrated that majority of Nurses perceived that limited infection control material and lack of knowledge regarding transmission of COVID-19 are the major barriers in infection control practice. Correlational analysis findings of present study as knowledge is significantly related to good practices.

The study has number of implicit limitations. Firstly, it is a cross-sectional study conducted during lockdown period, and institutional review board was not approached. Secondly, this survey responses mainly depend upon honesty and partly affected by recall ability and thus may subject to recall bias. Potential sample clustering might also limit the generalizability of study.

\section{Conclusion}

These findings suggest the need for effective and appropriate health education programs aimed at improving COVID-19 knowledge, thereby leading to implementation and maintenance of safe practices. Safe practices lead to prevent risk of spread of COVID-19 infection from patient to nurses and nurse to patient. MOHFW, Bangladesh should provide a comprehensive training programme, targeting all Nurse's to promote all precautionary and preventive measures of COVID19 , to achieve equilibrium in terms of clinical knowledge about COVID-19.

Acknowledgement: I would like to express my deepest since of gratitude, sincere and indebtedness to Prof. Dr. Md. Abdul Mukit Sarkar, MBBS, DCM, MHPEd, Professor and Head, Department of Community Medicine, Islami Bank Medical College, Rajshahi, Bangladesh, Prof. Dr. Cinmoy Kanti Das, MBBS, PhD, Professor, Department of Community Medicine, Rajshahi Medical College, Rajshahi, Bangladesh and Prof. Dr. Enayet Ullah, MBBS, PhD, Professor, Department of Community Medicine, Barind Medical College, Rajshahi, Bangladesh for their generous guidance's and suggestions to modification of study materials. I am also indebted to Deputy Director and Nursing Superintendent of Rajshahi Medical College Hospital, Rajshahi, Bangladesh for their unlimited guidance and assistance helped me to collect data. My special gratitude is due to my family for giving me proper support and encouragement from first to last of the studies.

\section{References}

1. Wang C, Horby PW, Hayden FG, Gao GF. A novel coronavirus outbreak of global health concern. The Lancet. 2020;395(10223):470-3

2. World Health Organization. Coronavirus disease (COVID19) Pandemic, Available at: https://www.who.int/emergencies/diseases/novel-coronavirus2019 [Accessed March 10 2020].

3. Infection prevention and control during health care when novel coronavirus (nCoV) infection is suspected n.d. https://www.who.int/publications-detail/infection-preventionand-control-during-health-care-when-novel-coronavirus(ncov)-infection-is-suspected- 20200125 (accessed April 11, 2020).

4. WHO. A Guide to Developing Knowledge, Attitude and Practice Surveys 2008.

5. Shigemura J, Ursano RJ, Morganstein JC, Kurosawa M, Benedek DM. Public responses to the novel 2019 coronavirus (2019-nCoV) in Japan: Mental health consequences and target populations. Psychiatry and clinical neurosciences. 2020;74(4):281

6. Li YC, Bai WZ, Hashikawa T. The neuroinvasive potential of SARS-CoV2 may play a role in the respiratory failure of COVID-19 patients. Journal of Medical Virology. 2020;92(6):552-5

7. Huang C, Wang Y, Li X, Ren L, Zhao J, Hu Y, Zhang L, Fan G, Xu J, Gu X, Cheng Z. Clinical features of patients infected with 2019 novel coronavirus in Wuhan, China. The lancet. 2020;395(10223):497-506

8. Guo YR, Cao QD, Hong ZS, Tan YY, Chen SD, Jin HJ, Tan KS, Wang DY, Yan Y. The origin, transmission and clinical therapies on coronavirus disease 2019 (COVID-19) outbreak-an update on the status. Military Medical Research. 2020;7(1):1-0

9. Zhong BL, Luo W, Li HM, Zhang QQ, Liu XG, Li WT, Li Y. Knowledge, attitudes, and practices towards COVID-19 among Chinese residents during the rapid rise period of the COVID-19 outbreak: a quick online cross-sectional survey. International journal of biological sciences. 2020;16(10):174552

10. WHO. Coronavirus n.d. https://www.who.int/healthtopics/coronavirus\#tab=tab_1 (accessed April 11, 2020).

11. Li JY, You Z, Wang Q, Zhou ZJ, Qiu Y, Luo R, Ge XY. The epidemic of 2019-novel-coronavirus (2019-nCoV) pneumonia and insights for emerging infectious diseases in the future. Microbes and infection. 2020;22(2):80-5

12. OECD Policy Responses to Coronavirus (COVID19)Treatments and a vaccine for COVID-19: The need for coordinating policies on R\&D, manufacturing and access, 29 May 2020

13. Hung LS. The SARS epidemic in Hong Kong: What lessons have we learned? Journal of the Royal Society of Medicine, 2003;96(8):374-378

14. Royal College of Nursing/Clinical/Infection prevention and control/ Clinical guidance for managing COVID-19

15. Fashafsheh I, Ayed A, Eqtait F, Harazneh L. Knowledge and Practice of Nursing Staff towards Infection Control Measures in the Palestinian Hospitals. Journal of Education and Practice. 2015;6(4):79-90

16. Johnson OE, Asuzu MC, Adebiyi AD. Knowledge and practice of universal precautions among professionals in public and private health facilities in Uyo, Southern Nigeria- a comparative study. Ibom Med J 2013;6(1): 9-19

17. Janjua NZ, Razaq M, Chandir S, Rozi S, Mahmood B. Poor knowledge predictor of non-adherence to universal precautions for blood borne pathogens at first level care facilities in Pakistan. BMC Infect Dis 2007;7:81 
18. Reda AA, Frisseha S, Mengistie B, Vanderweerd J. Standard precautions: occupational exposure and behavior of health care workers in Ethiopia. Plos One 2010;5 (12):e14420. 19. Giao H, Thi N, Han N, Khanh T Van, Ngan VK, Tam V Van, et al. Knowledge and attitude toward COVID-19 among healthcare workers at Knowledge and attitude toward COVID19 among healthcare workers at District 2 Hospital , Ho Chi Minh City. Asian Pac J Trop Med 2020;13:1-6

20. Bhagavathula AS, Aldhaleei WA, Rahmani J, Mahabadi MA, Bandari DK. Novel Coronavirus (COVID-19) Knowledge and Perceptions: A Survey on Healthcare workers. MedRxiv 2020:2020.03.09.20033381

21. Lai CC, Shih TP, Ko WC, Tang HJ, Hsueh PR. Severe acute respiratory syndrome coronavirus 2 (SARS-CoV-2) and coronavirus disease-2019 (COVID-19): The epidemic and the challenges. Int J Antimicrob Agents 2020;55

22. Muhammad S, Muhammad M, Saif R, Aqsa G, Sahar N, Ahmed Z, Azhar T, Muhammad M. Knowledge, attitude, practice and perceived barriers among healthcare professionals regarding COVID-19: A Cross-sectional survey from Pakistan. 2020

23. Huynh NG, Ngoc T, Nguyen TNH, Tran K, Ngân V, Vo T, Pham LA. Knowledge and attitude toward COVID-19 among healthcare workers at District 2 Hospital, Ho Chi Minh City. Asian Pacific Journal of Tropical Medicine. 2020;13.

24. Nemati M, Ebrahimi B, Nemati F. Assessment of Iranian Nurses' Knowledge and Anxiety toward COVID-19 during the Current Outbreak in Iran. Arch Clin Infect Dis 2020;In Press 25. Khan MU, Shah S, Ahmad A, Fatokun O. Knowledge and attitude of healthcare workers about middle east respiratory syndrome in multispecialty hospitals of Qassim, Saudi Arabia. BMC Public Health 2014;14:1-7

26. Nour MO, Babilghith AO, Natto HA, Al-Amin FO, Alawneh SM. Knowledge, attitude and practices of healthcare providers towards MERS-CoV infection at Makkah hospitals, KSA. Int Res J Med MedSci 2017;3:103-12 